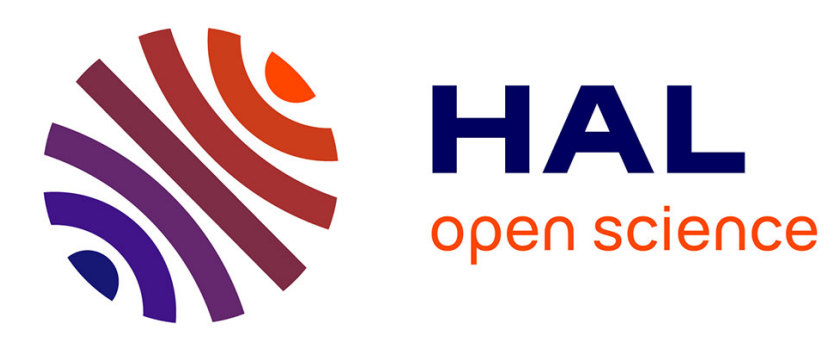

\title{
A New F.D.T.D. Algorithm for the Study of Ferrite with a Negative Effective Permeability
}

Ch. Melon, Thierry Monédière, F. Jecko

\section{To cite this version:}

Ch. Melon, Thierry Monédière, F. Jecko. A New F.D.T.D. Algorithm for the Study of Ferrite with a Negative Effective Permeability. Journal de Physique IV Proceedings, 1997, 07 (C1), pp.C1-135-C1136. 10.1051/jp4:1997145 . jpa-00255092

\section{HAL Id: jpa-00255092 https://hal.science/jpa-00255092}

Submitted on 1 Jan 1997

HAL is a multi-disciplinary open access archive for the deposit and dissemination of scientific research documents, whether they are published or not. The documents may come from teaching and research institutions in France or abroad, or from public or private research centers.
L'archive ouverte pluridisciplinaire HAL, est destinée au dépôt et à la diffusion de documents scientifiques de niveau recherche, publiés ou non, émanant des établissements d'enseignement et de recherche français ou étrangers, des laboratoires publics ou privés. 


\title{
A New F.D.T.D. Algorithm for the Study of Ferrite with a Negative Effective Permeability
}

\author{
Ch. Melon, Th. Monediere and F. Jecko
}

IRCOM-URA 356 du CNRS, Equipe "Electromagnétisme", Faculté des Sciences, 123 avenue Albert

Thomas, 87060 Limoges cedex, France

\begin{abstract}
Ferrite materials are used in many microwave devices (circulators,isolators ...) which work in a frequency range where the effective permeability $\mu$ eff of the ferrite can be either positive or negative. Many authors [1], [2] and [3] have applied the F.D.T.D. method to the study of saturated ferrite when $\mu$ eff is positive. The behaviour of the material is completly different when its effective permeability becomes negative [4]. In this paper a new 2D F.D.T.D. algorithm is developed to study ferrite when $\mu$ eff is negative. It is validated by computation of resonant frequencies and fields patterns of a ferrite resonant structure.
\end{abstract}

\section{THEORETICAL STUDY}

The F.D.T.D. method applied to ferrite consists in a discretization and resolution in time domain of the two curl's Maxwell equations and of the equation of motion of the magnetic moment. The classical discretization scheme (Fig 1) is due to YEE. In isotropic medium, $\mathrm{Hx}$ is calculated at $(A)$ point versus $\mathrm{Bx}$ and $\mathrm{Hy}$ at $(B)$ point versus $\mathrm{By}$. In anisotropic ferrites we need $\mathrm{Bx}$ and $\mathrm{By}$ at the same point $(\mathrm{A})$ to calculate $\mathrm{Hx}(\mathrm{A})$. The approximation $\mathrm{By}(\mathrm{A})=\mathrm{By}(\mathrm{B})$ is done and gives good results when $\mu$ eff $>0$ but is not accurate enough when $\mu$ eff $<0$. This is the reason why another scheme is presented (Fig 2 ) in this paper.

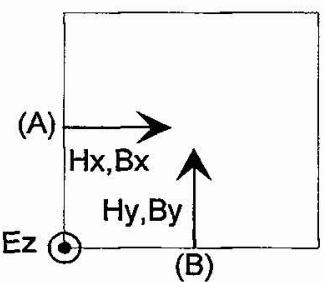

Figure 1: YEE scheme

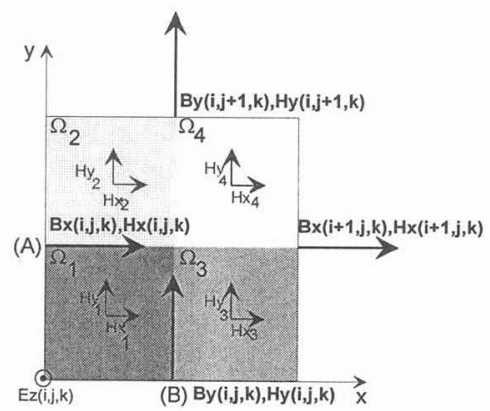

Figure 2: NEW scheme

With this scheme, $\mathrm{Hx}$ and $\mathrm{Hy}$ are calculated at the same points, chosen at the center of 4 domains $\Omega \mathrm{i}$ included in the mesh. $\mathrm{H}$ components are determined versus $\mathrm{Bx}$ and $\mathrm{By}$ known and constant in each domain $\Omega \mathrm{i}$. $\mathrm{Hx}(\mathrm{A})$ and $\mathrm{Hy}(\mathrm{B})$ are deduced by a linear interpolation from $\mathrm{Hxi}$ and Hyi previously calculated.

\section{RESULTS}

Validations are done by computation of resonant frequencies and fields patterns of a resonant structure made of a cylindrical ferrite resonator centered in a metallic cavity. The results obtained by the two schemes are compared to those given by an analytical method [5]. The characteristics of the structure are: radius of ferrite $15 \mathrm{~mm}$, radius of cavity $45 \mathrm{~mm}$, Ferrite: $\varepsilon_{\mathrm{r}}=14,4 \pi \mathrm{Ms}=900 \mathrm{G}, \mathrm{Hi}=200 \mathrm{Oe}$. Figure $3 \mathrm{a}$ presents the evolution of Ez versus frequency calculated by the two F.D.T.D. schemes. A good agreement appears when $\mathrm{P} 3 \mathrm{Ghz}(\mu \mathrm{eff}>0)$, there is an important difference in the amplitude of fields for $\mathrm{f}<3 \mathrm{Ghz}(\mu \mathrm{eff}<0)$. In order to explain this phenomena, fields patterns are presented on Fig $3 \mathrm{~b}$ and $3 \mathrm{c}$. Fig $3 \mathrm{~b}$ is the comparison between analytical results and the YEE F.D.T.D. algorithm results. A great dispersion appears in the F.D.T.D. 
computation showing the bad accuracy of this method. On Fig $3 \mathrm{c}$ fields are calculated using the new F.D.T.D. scheme and are compared to analytical results [5]. A good agreement appears showing the best accuracy of the new scheme.

\section{CONCLUSION}

A new F.D.T.D. algorithm has been presented to study ferrite when their effective permeability is negative. It has been validated on a two dimensional structure. It seems more accurate than the classical YEE scheme to treat mediums with high anisotropy. The application of this algorithm to three dimensional problems is now under consideration.

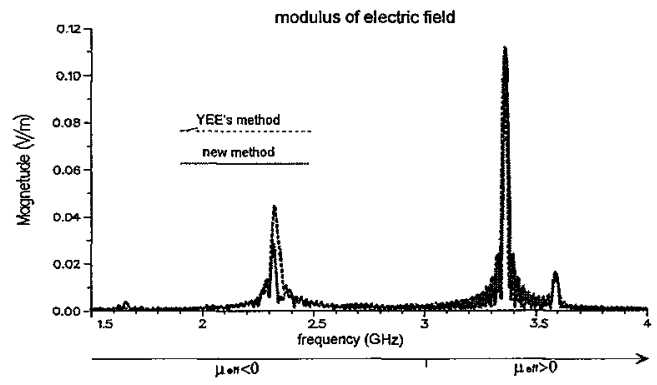

Figure 3a: Evolution of Ez versus frequency
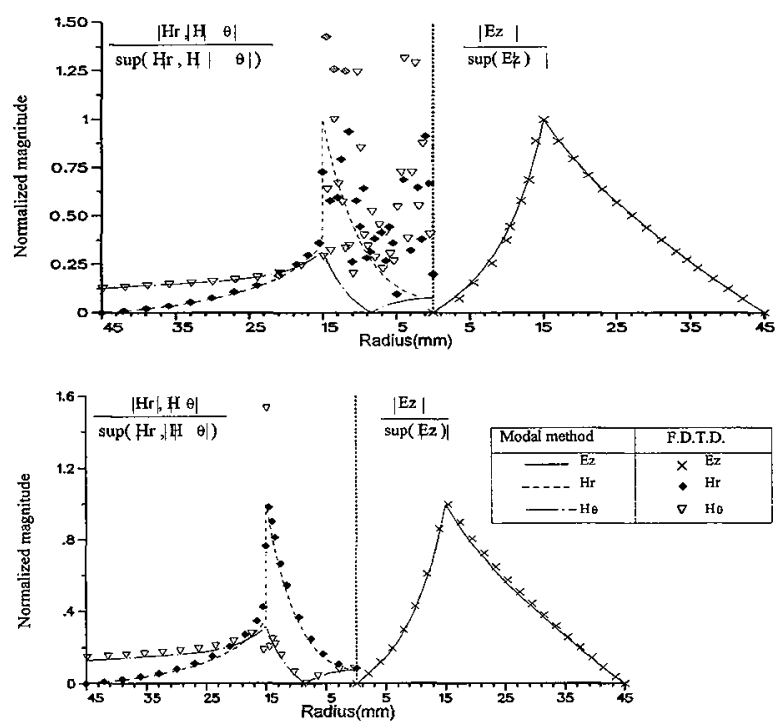

Figure 3(b)(c): Fields patterns: Comparison between FDTD and Modal method TM1 $10 \mathrm{~F}=2.32 \mathrm{GHz} \mu \mathrm{eff}=-1.12$

\section{References}

[1] A Reineix, T Monediere and F Jecko, "Ferrite Analysis Using the Finite-Difference Time Domain (F.D.T.D.) method" Microwave and Optical Technology Letters, Volume $5 \mathrm{n}^{\circ} 13$ (1992) 685-686, Dec5.

[2] Pereda J.A and Al," A treatement of magnetized ferrites using the F.D.T.D. method" I.E.E.E. Microwave Guided Wave Letters, Vol 3 n5 (1993) 136-138.

[3] M Okoniewski and E Okoniewska,"The F.D.T.D. analysis of magnetized ferrites: A more efficient algorithm" I.E.E.E. Microwave and guided wave letters, vol $4 \mathrm{n}^{\circ} 6$ (1994).

[4] M.S Shoda and N.C Srivastava, "Microwave propagation in ferrimagnetics" Plenum press New York and London.

[5] M Latrach, T Monediere anf F Jecko, "A new design of cylindrical closed triplate ferrite resonators compared with magnetic wall approximation", I.E.E.E. Transactions on Magnetics, vol 26 n5 (1990) 2856-2862. 